\title{
Sureerer \\ Overall safety of on-pump and off-pump CABG surgery is similar
}

The first results of CORONARY, a randomized trial of on-pump versus offpump CABG surgery, have been published in the New England Journal of Medicine and presented at the 2012 ACC Scientific Sessions. The 30-day outcome data showed no overall difference in the safety of the two surgical techniques.

On-pump CABG surgery is performed during cardiopulmonary bypass, whereas off-pump CABG surgery is performed on a beating heart. The latter technique was developed to avoid perioperative complications related to bypass.

CORONARY is the largest study to date comparing the outcomes of the two types of surgery. The early results, from 4,752 patients, show no significant difference in the safety of the techniques in terms of risk of death, nonfatal stroke, nonfatal myocardial infarction, or new renal failure requiring dialysis. Rates of respiratory and bleeding complications, and acute kidney injury, were lower in patients who underwent off-pump compared with on-pump CABG surgery. However, the rate of early revascularization procedures was higher in the patients who were treated off pump (HR 4.01, 95\% CI 1.34-12.0, $P=0.01)$.

Lead investigator André Lamy believes that these data will reassure patients and surgeons that both types of CABG surgery are effective. "It is [up] to the surgeon to select which technique will bring further benefits to the [individual] patient," he explains. The trial is ongoing and neurocognitive outcome results are expected within 6 months.

Ellen F. Carney

Original article Lamy, A. et al. Off-pump or on-pump coronary-artery bypass grafting at 30 days. N. Engl. J. Med. doi:10.1056/NEJMoa1200388 